\title{
Moving from the sidelines to the playing field

\author{
Developing a relationship with student athletics
}

$\mathbf{T}$ he Vanderbilt University Library, in collaboration with the university's Department of Athletics Stratton Foster Academic Support Center, established an initiative to better acquaint the counselors at the center with the library and its resources. Through conversation, both sides realized there were many opportunities to make the relationship stronger, resulting in year-round support for student athletes. The partnership, now in its fourth year, has evolved to meet the needs of both the students and support staff.

\section{Invitation to play and kick off}

As part of a larger initiative to establish more formal relationships with campus partners, the Vanderbilt University Library's Student Outreach and Engagement Committee (SOEC) contacted the director of the Stratton Foster Academic Support Center. SOEC wanted to explore the possibility of setting up a formal conversation with the counselors to see how the library could better support the center's work with student athletes. The counselors agreed to meet with several librarians. At the initial meeting, counselors expressed their concerns regarding the students' struggles with research tasks, such as using the library databases, navigating the library website, and citing sources.

An outcome from the first meeting was the creation of the "Train the Trainer" session designed specifically for the counselors. In this session librarians highlighted library services, contact information for the subject librarians, research guides, and available technologies, such as laptops and iPads, for checkout. Given the counselors' regular contact with the student athletes, the librarians believed the counselors were in a position to reinforce the library's role in student success. However, both parties wanted a product designed specifically for the students. This resulted in an invitation for the library to participate in the center's annual Summer Bridge program. ${ }^{1}$

\section{Game on}

As part of the Summer Bridge program, librarians designed activities to introduce new student athletes to the library and its services. The first was a tour led by subject librarians, where students visited the campus library associated with their intended major. The second was an in-depth instruction session about the library's services and resources.

\footnotetext{
Kate Costin, formerly of the Vanderbilt University Library, is now research librarian at the Congressional Research Service, email: kcostin@crs.loc.gov, and Pamela J. Morgan is subject librarian at Vanderbilt University Library, email: pamela.j.morgan@vanderbilt.edu

CRS Disclosure: "The views expressed herein are those of the author and are not presented as those of the Congressional Research Service or the Library of Congress."
}

(C) 2019 Kate Costin and Pamela J. Morgan 
Librarians wanted to provide the students with an engaging and festive atmosphere. The solution? A game. Librarians chose FlipQuiz to design a quiz show-like game consisting of questions that reinforced the session's learning objectives. This choice intended to capitalize on the student athlete's competitive nature, while ensuring they demonstrated $\mathrm{u} n \mathrm{~d}$ e $\mathrm{r}$ standing of library services and resources. The quiz consisted of several

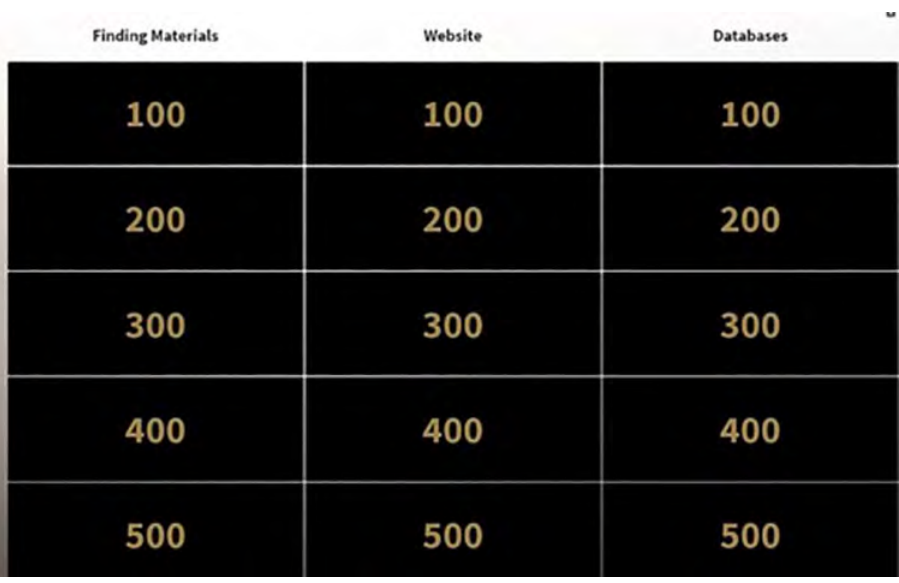

FlipQuiz game board with categories.

categories, including technology, finding materials, website, and databases. In order to support the session, librarians created a research guide, using the following learning objectives.

- $\mathrm{L}$ O cate the list of subject librarians in Commodores : the great book of Vanderbilt sports history and trivia" and what is the call number?
Which library has the book "Know your Vanderbilt tact a librarian for assistance.

- Find the research guides with subjectrelated resources in order to successfully complete coursework.

- Distinguish steps in the research cycle in order to break the process down into manageable parts.

- Format citations in order to properly provide attribution to sources. provided students a chance to navigate the library's website. In the event some students did not have a chance to view the guide, the first part of the instruction session involved a lecture/ tour of the research guide, then moving on to the quiz/ competition.

- Access the A-Z List of Databases in order to select the most appropriate sources for information.

Prior to the session, counselors asked stujective was to expose students to included in the quiz, but not necessarily covered in the session's lecture. Accessing the guide prior to the session also The game resulted in lively student participa-
tion, and the librarians received positive feedback from the counselors after the session.

\section{The library's away game: Reference service at study halls}

After the summer tours and instruction session, librarians saw an opportunity for embedded librarianship by providing reference 
service at the student athlete study halls. This service seemed a natural fit, providing assistance in a space intended for research and academic work. The service began in the fall semester with one slot on Monday afternoons and expanded in the spring semester to include Thursday evenings.

While the number of interactions was small, the students using library office hours expressed great appreciation for the service. Librarians were able to spend quality time with the students discussing a variety of research components, such as assignment interpretation,

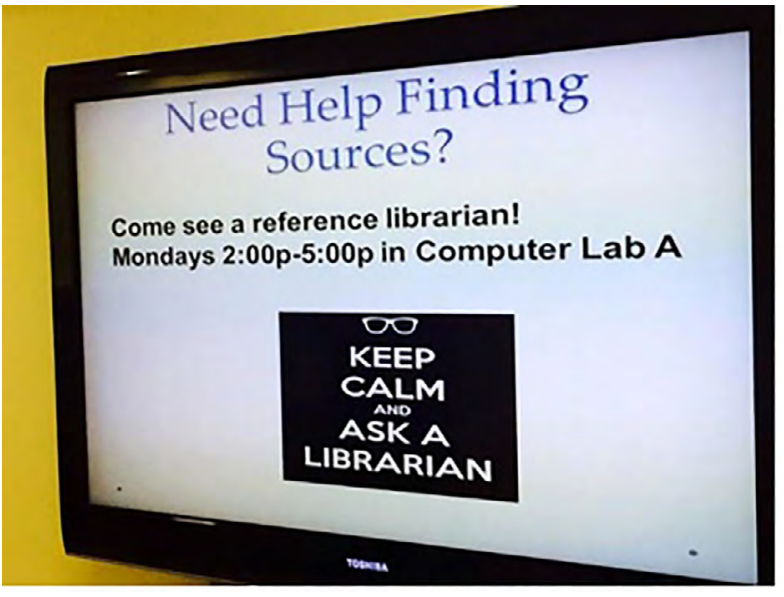

Signage at Stratton Foster Center. to know what could be improved moving forward.

\section{Satellite service}

The counselors were pleased with the librarians' presence, concluding "more is better." Suggestions for improvements included: identifying ap-

propriate resources, and proper citation formatting. The counselors were very enthusiastic about this initiative, and assisted in promoting the service by creating various publicity materials and signage. As the semester progressed, students became more aware of the type of help librarians could provide, sometimes scheduling research consultations outside of study hall hours.

\section{Playback and modifying game plans}

The success of the partnership between the library and the Stratton Foster Academic Support Center in its first year far exceeded the expectations of the librarians. The first year established relationships with the counselors and set the stage for ways in which the partnership could evolve the following summer. Prior to the second Summer Bridge program, library staff sat down with the counselors to discuss the tours, the instruction session, and the satellite service. The librarians wanted
- $\quad \mathrm{O} \mathrm{n}$ tinuing service twice a week, with the possibility for additional hours at targeted times during the semester;

- $\quad \mathrm{c}$ a $\mathrm{p}$ turing more information about who uses the service and why (source help, citation help, etc.); and

- helping the counselors create more publicity to promote library services both inside and outside of study halls.

In the second year, student usage of the service remained steady, although librarians had hoped for greater numbers. Still, those students who did take advantage of the service expressed appreciation for library service at the study halls.

The second year also meant athletes began to recognize librarians on campus and felt more comfortable reaching out for assistance. Counselors remained enthusiastic about the service, and coaches who knew of the service also were extremely appreciative. Librarians tweaked the service to offer reference hours on Wednesday evenings, with the hope that more students would use it.

\section{Summer orientation and instructional game}

Librarians believed the website tour/lecture 
was only partially engaging, with the competitive element of the game garnering far more enthusiasm and engagement than the lecture. Counselors liked the game format but wanted more interaction with the databases. Librarians devised the following modifications:

- devoting the whole hour to the game, discarding the formal presentation.

- paring the question categories down to three: website, finding materials, and databases; and

- grouping students into teams to make use of peer learning.

Librarians rewrote questions to incorporate more active learning . The quiz required more e n g a g e ment with the library website and databases.

\section{3} Staff divid-

ed the students into teams, and each team competed for points by correctly answering questions. Recognizing the need to keep some instructional element, librarians interspersed the game with timeouts, teachable moments with additional context regarding the service or concept highlighted at that particular moment in the game. For example, after the question, "Who is the liaison for English?" students were reminded that the library is staffed with many subject specialist, who are available to assist in their research needs.

The game remained popular with the students, and the teams made the event lively and fun. According to the counselors, the athletes were more engaged at the library than at any other point during their various orientation sessions.
The third year saw further modifications for the library instruction session. Counselors emphasized the role of positive engagement with the competition. However, the counselors wanted more opportunities for students to go online and practice using the databases. The librarians needed to develop an online scavenger hunt/competition where students had to work to find library materials. While FlipQuiz worked well for the first two years, librarians set it aside in favor of Kahoot!

Kahoot! allowed librarians to design questions that would require website navigation and database use, along with a time limit to answer a question. Quiz questions included locating specific librarians, key subject databases, database tools, and specific articles. Once librarians designed the quiz, they compiled a "Ten Tips in Ten Minutes" lecture that would address all

the questions. This structure was a departure from devoting the whole hour to the game, but the game/hands on time remained the focus.

\section{Conclusion}

Now in its fourth year, the Vanderbilt Libraries' partnership with the Stratton Foster Academic Support Center offers student athletes a variety of ways to engage with the library and the librarians throughout the academic year. The collaboration has increased awareness of library services and support among students and counselors. Librarians benefit by working with a population of students they might not otherwise see, resulting in the librarians' ability to shape collections and services based on these interactions. Librarians are also proud to participate in 
the Summer Bridge program, a recipient of the Model Practices Award for Student Support Services by the National Association of Academic and Student-Athlete Development Professionals. ${ }^{2}$ It is rewarding to hear from counselors how much they value the library's on-sight reference services and that student athletes appreciate the support. Perhaps the best part of the partnership for the librarians is seeing the student academic honors year after year. Vanderbilt student athletes have a strong academic performance.

Several teams have either perfect Academic Performance Rates (APR) or the best APR in the Southeast Conference (SEC). ${ }^{3}$ Librarians take great pride in playing a part in these accomplishments and enjoy seeing familiar names on the SEC Honor Roll plaques. Deans and directors of other libraries serving SEC schools have taken notice and have expressed interest in learning about the service. Even if numbers of transactions are small, the quality time with the students is well worth it, and the focus is now on maintaining a strong relationship with the academic counselors and providing flexible reference, outreach and instruction, and services that adapt to student needs.

\section{Tips from our playbook}

- Score major points with a game. Whether it's a scavenger hunt, Jeopardy style quiz, or other game, consider a competitive element with athletes. FlipQuiz was by far the most engaging portion of the outreach portfolio. Vanderbilt University Athletics ended up using it for their own activities. Even as needs changed, the game remained.

- Keep up with the stats. Are the athletes you work with listed on honor rolls? Let them know you notice. It will be appreciated. At Vanderbilt, librarians use academic success stories and APR information to promote library services.

- Develop relationships with your counselors. You will find a receptive audience, as academic counselors welcome assignment alerts, tips and tricks for library research, notifications about research workshops, etc. You both share a goal—student success.

- Know when to pass. Be familiar with other campus resources, such as writing centers, software labs, tutoring, so that you can make appropriate referrals. Many campus organizations make their resources available online, so you can include information about them in a research guide.

\section{Notes}

1. h t t p s://Ww . y outube.com /watch? $\mathrm{v}=\mathrm{d} 3$ AEgnlJNoQ\&t=1s.

2. https://news.vanderbilt.edu/2018 /06/29/academic-support-center-for-student -athletes-wins-national-model-practices -award/.

3. https://vucommodores.com/news /2017/8/18/GPA_highest_in_VU_athletics _history.aspx. 2

("ACRL bonors the 2019 award winners, part 1," continues from page 200)

SAGE-CQ Press, sponsor of the award, will present the $\$ 1,000$ award and plaque to Kellam during the ALA Annual Conference.

"Lynda Kellam has provided distinguished service in political science librarianship," said Award Chair Erin Ackerman, social sciences librarian at the College of New Jersey. "The tools and programs she has created have an enormous impact on the profession as a whole and individual librarians.
"Lynda created and continues to coordinate the webinar series 'Help! I'm an Accidental Government Information Librarian," Ackerman continued. "These webinars cover a wide range of topics from Brexit to Census data to the U.S. Geological Survey. With this series-now in its ninth year-as well as in her work on academic databrarianship, Lynda creates opportunities for librarians to connect and share the information that helps us do our jobs better." 2 